\title{
Congenital fistulae of the lacrimal gland
}

\author{
MARTIN A O'CONNOR, DESMOND B ARCHER, AND PATRICIA M HART \\ From the Department of Ophthalmology, the Queen's University of Belfast, and the Eye and Ear Clinic, \\ Royal Victoria Hospital, Belfast
}

SUMMARY A 15-year-old female was found on routine clinical examination to have bilateral asymptomatic congenital fistulae of the lacrimal glands. The fistulae opened into the conjunctival sac at the external canthus of both eyes. Temporary occlusion of these openings produced an immediate and significant reduction in tear secretion in both eyes.

Congenital fistulae of the lacrimal gland are rarely reported. Since their original description by Beer' 16 cases have been recorded in the literature, only one of which was bilateral. ${ }^{2}$

\section{Case report}

A 15-year-old female presented in November 1983 with a three-week history of itchy, discharging eyes. Her symptoms had failed to respond to topical chloramphenicol drops prescribed by her family doctor. The patient had no previous ocular complaints but gave a history of hay fever and had suffered from eczema as an infant. Visual acuity was $6 / 6$ unaided right and left, and the eyes were structurally sound apart from a mild bilateral follicular conjunctivitis with associated mucopurulent discharge. Conjunctival swabs from both eyes were bacteriologically sterile. Cytological examination of scrapings from the lower tarsal conjunctiva of each eye showed a mixed infiltrate of neutrophils, lymphocytes, and eosinophils; inclusion bodies were absent. On the basis of these findings a diagnosis of allergic conjunctivitis was made, and the patient was treated with topical betamethasone $0 \cdot 1 \%$ drops three times daily to both eyes.

Ten days later the patient was asymptomatic, and signs of conjunctival inflammation were less. Examination on this occasion revealed a small opening on the conjunctival aspect of the external canthus of the right eye, and a similar opening was present at the external canthus of the left eye (Fig. 1). When the eyelids were held apart and drawn away from contact with the globes, a small amount of clear fluid was seen to discharge from each orifice on to the skin at the

Correspondence to Mr M O'Connor, FRCSI, Eye and Ear Clinic, Royal Victoria Hospital, Belfast BT12 6BA, Northern Ireland. external canthi. A $0.5 \mathrm{~mm}$ lacrimal probe was passed without difficulty for a distance of approximately 8 $\mathrm{mm}$ from the right orifice and for a distance of almost $10 \mathrm{~mm}$ from the left orifice. A roentgenogram taken after injection of contrast medium into both of these openings clearly demonstrated the presence of a fistula extending upwards towards the lacrimal gland on each side (Fig. 2). There was no clinical abnormality of the lacrimal glands, and the lacrimal passages on both sides were normal. A Schirmer 1 test showed greater than $20 \mathrm{~mm}$ of wetting in both eyes after five minutes. However, after occlusion of each orifice for 10 minutes with a silicone rod of 0.7 mm diameter a repeat Schirmer 1 test showed only 11 $\mathrm{mm}$ of wetting in the right eye and $7 \mathrm{~mm}$ in the left eye. The silicone rods were then removed, and 10 minutes later the Schirmer 1 test showed wetting of $22 \mathrm{~mm}$ in the right eye and $18 \mathrm{~mm}$ in the left. This sequence was repeated on two occasions with similar results.

The patient had no other ocular or systemic congenital abnormalities. Examination of other family members including both parents, five siblings, and the maternal grandparents was negative.

\section{Discussion}

Congenital fistula of the lacrimal gland is a rare anomaly. Blanksma and van de $\mathrm{Pol}^{2}$ reviewed the literature and found 13 cases of unilateral fistulae to which they added the first recorded case of a bilateral occurrence. We are aware of two additional reports, ${ }^{34}$ both of which describe unilateral fistulae.

Patients with congenital fistula of the lacrimal gland commonly present with epiphora ${ }^{3-9}$ or with a purulent discharge from a fistula which has undergone cystic dilatation with secondary infection. ${ }^{2}$ It is 


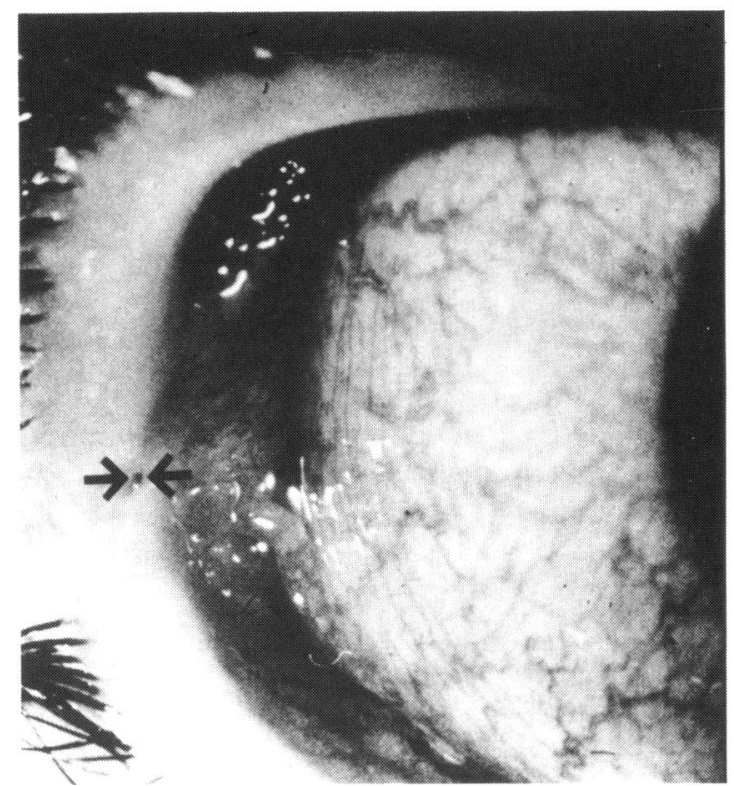

Fig. 1a Right eye.

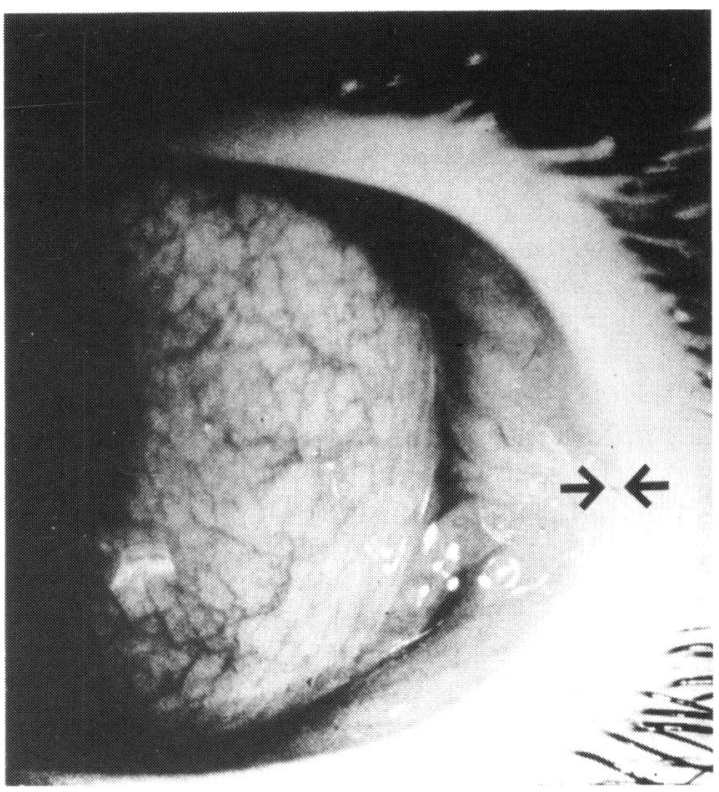

Fig. 1b Left eye.

Figs. 1a b The external canthi of both eyes showing the orifices of the lacrimal gland fistulas (arrows).

interesting that in spite of the congenital nature of these fistulae the clinical presentation is often delayed for many years after birth. ${ }^{28}$ This is probably related to the effect of evaporation on the discharge, which is often small in amount and intermittent in nature. ${ }^{10}$ In the present case the patient gave no history of epiphora, and discovery of the fistulae was accidental during routine clinical examination. This is not surprising, since each fistula opened into the conjunctival sac at the external canthus, so that the discharge from these openings merged with the tear film. Our patient will probably remain asymptomatic unless one of the fistulae becomes infected, as occurred in the case reported by Blanksma and van de $\mathrm{Pol}^{2}$ in which bilateral fistulae had remained asymptomatic for 35 years and the orifices of the fistulae were similar in location to those in the present case.

Although the discharge of tears from fistulae of the lacrimal gland is usually slight, an interesting feature in our patient was the finding that temporary occlusion of the orifices repeatedly produced a significant reduction of $50 \%$ or greater in tear secretion in both eyes as determined by the Schirmer 1 test. Putterman ${ }^{3}$

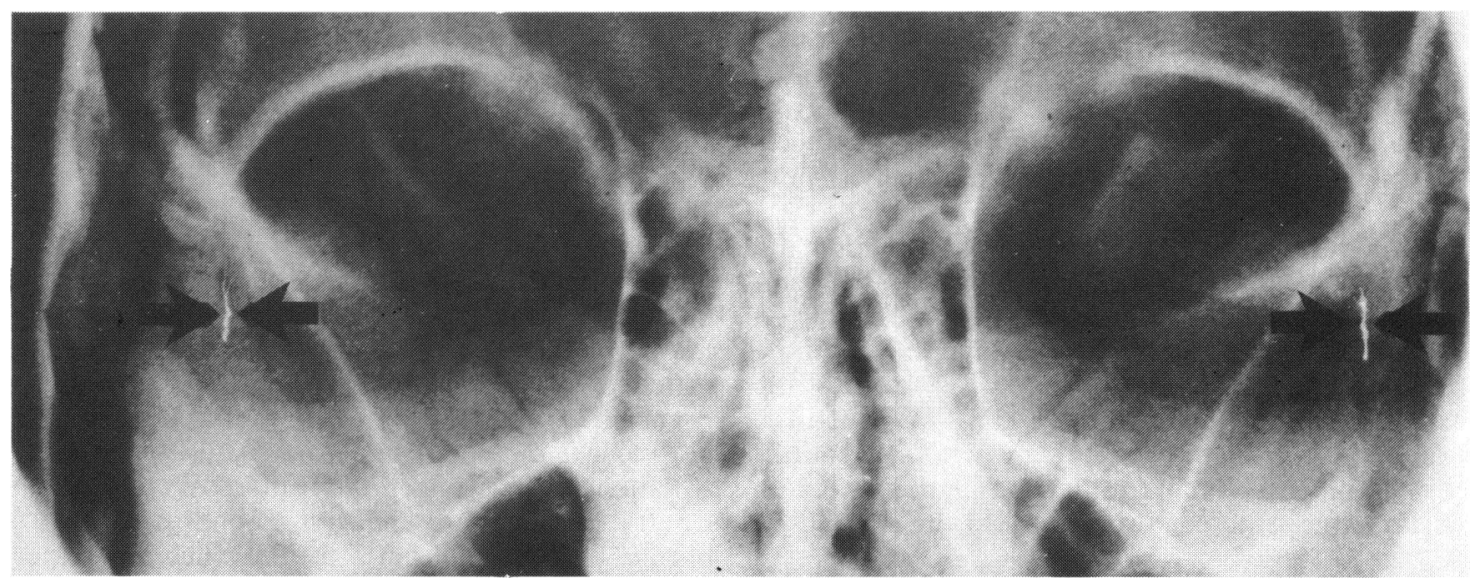

Fig. $2 X$-ray contrast photograph showing contrast medium outlining both fistulas (arrows). 
found an increase in tear secretion of similar magnitude following transplantation of a fistula of the lacrimal gland from the external eyelid to the conjunctival sac. Our finding leads us to suggest that the fistulae in the present case may represent true lacrimal ductules which are aberrant in position. Desai" points out that, while the majority of the lacrimal ductules normally open into the temporal part of the superior fornix, a larger ductule called the inferolateral duct traverses the lateral portion of the gland and, passing deep to the conjunctival epithelium, opens below and lateral to the main openings. We believe that the fistulae in the present case represent an anomaly in which during development of the inferolateral ducts the latter open into the conjunctival sac at a lower level than normal.

The finding that the fistulae in this case contribute significantly to the overall tear secretion in both eyes will be an important consideration should the question of surgery arise. In that event the approach suggested by Putterman, ${ }^{3}$ Terlinck, ${ }^{5}$ and Malhotra, ${ }^{7}$ in which the fistula is transplanted into the upper conjunctival fornix, would be the treatment of choice rather than the alternative method used by Blanksma and van de $\mathrm{Pol}^{2}$ and by Ling, ${ }^{8}$ in which the fistula along with an adjoining portion of lacrimal gland is completely excised.

\section{References}

1 Beer SJ. Lehre von den Augenkrankheiten. Vienna: Heubner und Wolfe, 1817; 2: 186.

2 Blanksma LJ, Pol B van de. Congenital fistulae of the lacrimal gland. Br J Ophthalmol 1980; 64: 515-7.

3 Putterman AM. Eyelid epiphora secondary to lacrimal gland fistula. Ophthalmic Surg 1980; 11: 682-5.

4 Bergdolt K, Heimke U. Congenital fistula of the lacrimal gland. Klin Monatsbl Augenheilkd 1980; 176: 972-4.

5 Terlinck H. Ein Fall von Angeborener Fistel der Tränendrüse. $Z$ Augenheilkd 1910; 24: 522-3.

6 Damato FJ. Congenital fistula of the lacrimal gland. $\mathrm{Br} \mathrm{J}$ Ophthalmol 1956; 40: 506-8.

7 Malhotra M. Congenital fistula of the lacrimal duct. $\mathrm{Br} J$ Ophthalmol 1956; 40: 559-61.

8 Ling WP. Anomalous duct of lacrimal gland associated with other congenital anomalies. Am J Ophthalmol 1926; 9: 1-2.

9 Desai HG. Congenital fistula of the lacrimal gland. $\mathrm{Br} J$ Ophthalmol 1967; 51: 206-7.

10 Duke-Elder S. Congenital deformities. System ofophthalmology. London: Kimpton, 1964; 3 (2): 921-3. 